\title{
Type II Natural Killer T Cells that Recognize Sterol Carrier Protein 2 Are Implicated in Vascular Inflammation in the Rat Model of Systemic Connective Tissue Diseases
}

Yusuke Nishioka, ${ }^{*}$ Madoka Yamaguchi, ${ }^{*}$ Ai Kawakami, ${ }^{*}$ Maya Munehiro, ${ }^{\dagger}$ Sakiko Masuda, ${ }^{\ddagger}$ Utano Tomaru,${ }^{\S}$ and Akihiro Ishizu

From the Graduate School of Health Sciences, ${ }^{*}$ the Undergraduate School of Health Sciences, ${ }^{\dagger}$ and the Faculty of Health Sciences, ${ }^{\ddagger}$ Hokkaido University, Sapporo; and the Department of Pathology, ${ }^{\S}$ Hokkaido University Graduate School of Medicine, Sapporo, Japan

Accepted for publication September 13, 2016.

Address correspondence to Akihiro Ishizu, M.D., Ph.D., Faculty of Health Sciences, Hokkaido University, Kita-12, Nishi-5, Kita-ku, Sapporo 0600812, Japan. E-mail: aishizu@med.hokudai.ac.jp.

\begin{abstract}
We previously generated a rat model that developed systemic connective tissue diseases, including synovitis, myositis, and small-vessel vasculitis (SVV), and established a vascular endothelial cellreactive T-cell clone, VASC-1, from the model. VASC-1 was determined to be a type II natural killer T-cell clone. In this study, we attempted to identify the antigen recognized by VASC-1. The monkey-derived cell line COS-7 was used because VASC-1 does not bind naturally to COS-7, although the amino acid sequences are well conserved between monkey CD1d and rat CD1d. We generated 98 COS-7 clones transfected with miscellaneous rat cDNA and screened them for VASC-1 binding. Consequently, we found one clone, 4D2, which could bind to VASC-1. Sequencing identified the rat cDNA introduced into 4D2 as sterol carrier protein 2 (SCP2). When VASC-1 was co-cultured with SCP2 knockdown rat vascular endothelial cells, VASC-1 binding was reduced significantly. Moreover, we designed a series of rat SCP2 peptides and introduced them into COS-7 cells. On the basis of VASC- 1 binding and proliferation, we revealed that the peptide $\mathrm{rSCP}_{518-532}$ included the epitope recognized by VASC-1. Furthermore, immunization with $\mathrm{rSCP}_{518-532}$ accelerated the development of SVV in the rat model. The collective findings suggest that type II natural killer T cells reactive with autologous SCP2 are implicated in vascular inflammation in the rat model. (Am J Pathol 2017, 187: 176-186; http://dx.doi.org/10.1016) j.ajpath.2016.09.014)
\end{abstract}

We previously generated a rat model that developed systemic connective tissue diseases, including synovitis, myositis, and small-vessel vasculitis (SVV). ${ }^{1}$ In this model, a predominant infiltration of mononuclear cells was observed in the synovial and cardiac tissues and skeletal muscles and around small vessels in the systemic organs. An autoimmune mechanism could be involved in the pathogenesis because several autoantibodies, such as antinuclear and anti-DNA antibodies, were detected in the serum. The presence of hyperreactivity of peripheral $\mathrm{T}$ cells, ${ }^{2}$ disordered differentiation of T cells in the thymus, ${ }^{3}$ and functional impairment of regulatory $\mathrm{T}$ cells ${ }^{4}$ had been found in the model. In addition, we recently established a T-cell clone reactive with autologous vascular endothelial cells from the rat model and designated the clone as
VASC-1. ${ }^{5}$ VASC-1 was determined to be a clone of natural killer T (NKT) cells because this clone recognized a certain antigen presented by CD1d.

NKT cells belong to a unique subset of T cells that share surface markers and function with natural killer (NK) cells and play important roles in the immune response. ${ }^{6}$ The hallmark of NKT cells is their capacity to recognize antigens

Supported by grant-in-aid 26293082 from the Ministry of Education, Culture, Sports, Science and Technology of Japan (A.I.), a grant for Research on Rare and Intractable Vasculitis from the Ministry of Health, Labor and Welfare of Japan (A.I.), and grant 15ek0109121 from the Japan Agency for Medical Research and Development (A.I.).

Y.N., M.Y., and A.K. contributed equally to this work.

Disclosures: None declared. 
presented by class I major histocompatibility complex-like CD1d. ${ }^{7,8}$ Among the NKT cells, two major subsets, namely, type I and type II, have been noted. ${ }^{8-10}$ Type I NKT cells are characterized by the expression of a conserved $\mathrm{T}$-cell receptor (TCR) $\alpha$-chain (V $\alpha 24-\mathrm{J} \alpha 18$ in humans and $\mathrm{V} \alpha 14-\mathrm{J} \alpha 18$ in rodents) that pairs with a limited repertoire of $\beta$-chains. ${ }^{11-13}$ This type of cell, also called invariant NKT cells, can bind to a marine sponge-derived glycolipid, $\alpha$-galactosylceramide $(\alpha$-GalCer), presented by CD1d. In general, it is considered that type I NKT cells can recognize microorganism-derived glycolipids presented by CD1d and trigger both the innate and acquired immune responses against the microorganism. On the contrary, type II NKT cells express a more variable TCR repertoire and do not respond to stimulation with $\alpha$-GalCer. This type of cell can recognize sulfatides and peptides presented by CD1d. ${ }^{7,8,14,15}$ Interestingly, NKT cells reactive with autologous peptides (suggestive of type II phenotype) exhibit an immunosuppressive property in healthy mice. ${ }^{16}$ It can be considered that the immunoregulatory mechanisms are mediated by type II NKT cells in healthy individuals as follows. After, cells injured by an immune reaction express autologous peptides on CD1d, type II NKT cells that recognize the autoantigens produce immunosuppressive cytokines to prevent an excessive spread of inflammation.
The NKT cell clone, VASC-1, established from the rat model of systemic connective tissue diseases, exhibited a TCR use other than the type I invariant TCR $\alpha$-chain and did not bind to $\alpha$-GalCer-loaded CD1d; therefore, it was regarded as a type II NKT cell clone. ${ }^{5}$ Because VASC-1 produced proinflammatory cytokines after an interaction with autologous vascular endothelial cells, a functional impairment of the immunoregulatory autoreactive type II NKT cells could be present in the rat model. In this study, we attempted to identify the antigen recognized by VASC-1 and discovered an intracellular lipid transfer molecule, sterol carrier protein 2 (SCP2), as one of the autoantigens.

\section{Materials and Methods}

\section{Rats}

The rat model of systemic connective tissue diseases established in our laboratory ${ }^{1}$ and maintained under specific pathogen-free condition was used. These rats were transgenic for the env-pX gene of human T-cell leukemia virus type I. The transgene was expressed ubiquitously in the systemic organs, including hematopoietic cells. Because the transgene coded the transcription factor p40tax, which could disturb the ordinary transcription in the cells but did not code other viral

Table 1 Rat SCP2 Peptides

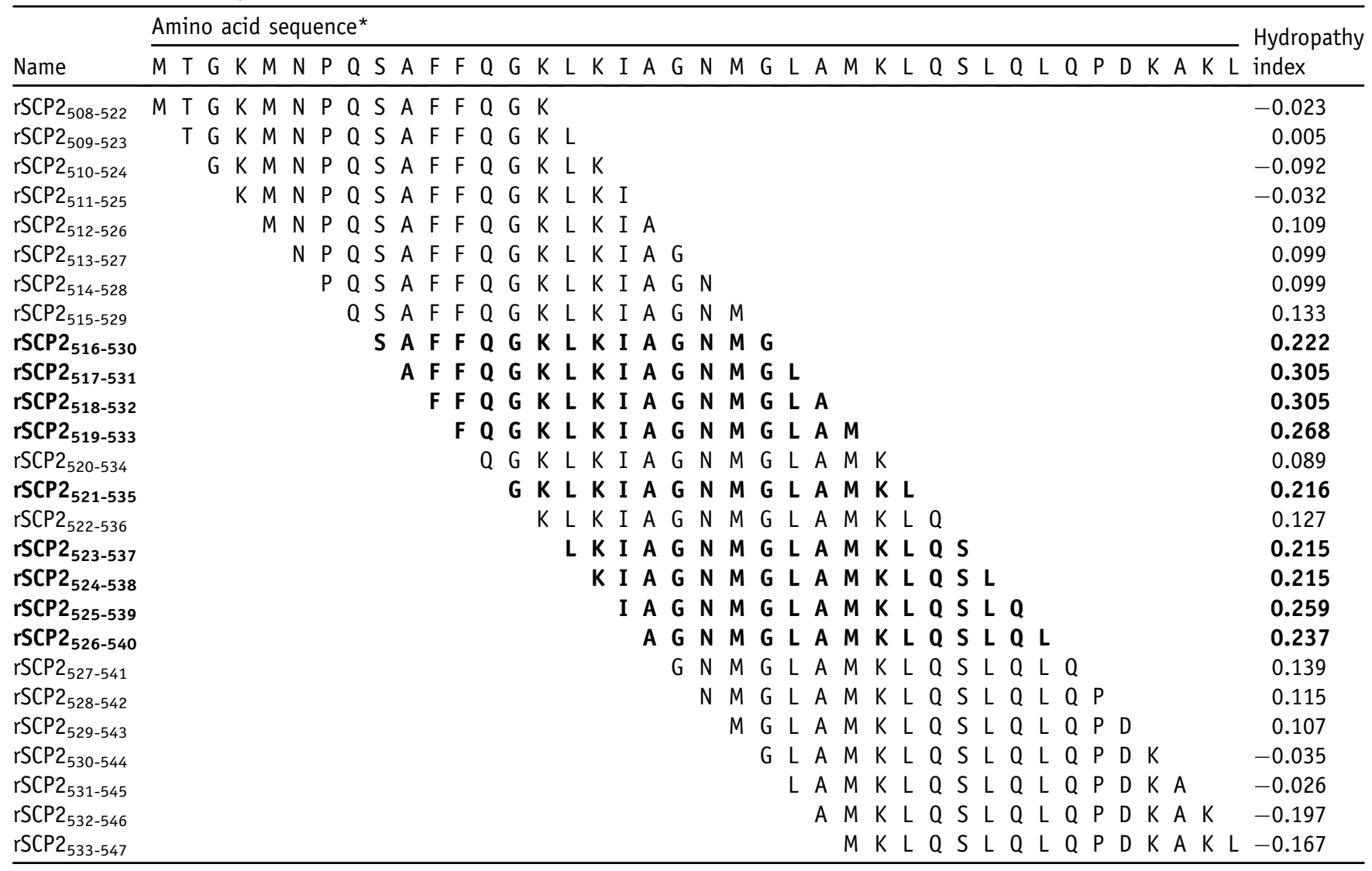

The boldface peptides represent those with a hydropathy index $>0.200$.

*The inserted region in 4D2. 
constructive proteins, these rats were considered as models with abnormal gene transcription rather than simple models of human T-cell leukemia virus type I infection. Experiments were performed in accordance with the Guidelines for the Care and Use of Laboratory Animals in Hokkaido University (permission No. 10-0029, 15-0034).

Cells

The rat inferior vena cava-derived vascular endothelial cells (RECs) and REC-reactive type II NKT cell clone, VASC-1, were established in our laboratory. ${ }^{5,17}$ RECs were maintained in RPMI 1640 medium containing 10\% fetal bovine serum (FBS) and $5 \times 10^{-5} \mathrm{~mol} / \mathrm{L} 2$-mercaptoethanol (2-ME). VASC-1 was maintained in RPMI 1640 medium containing $20 \% \mathrm{FBS}, 5 \times 10^{-5} \mathrm{~mol} / \mathrm{L} 2-\mathrm{ME}$, and $0.01 \mu \mathrm{g} /$ $\mathrm{mL}$ recombinant rat IL-2 (R\&D Systems, Minneapolis, MN). The monkey kidney-derived fibroblastic cell line, COS-7, was maintained in Dulbecco's modified Eagle's medium (DMEM) containing 10\% FBS.

\section{Co-Culture of VASC- 1 with RECs or COS-7}

RECs or COS-7 was grown subconfluently in a well of sixwell plates $\left(1 \times 10^{5}\right.$ per well $)$ at $37^{\circ} \mathrm{C}$. VASC- $1\left(2 \times 10^{5}\right.$ per well) was co-cultured with the cells in RPMI 1640 medium containing $20 \% \mathrm{FBS}, 5 \times 10^{-5} \mathrm{~mol} / \mathrm{L} 2-\mathrm{ME}$, and $0.01 \mu \mathrm{g} / \mathrm{mL}$ recombinant rat IL-2 overnight at $37^{\circ} \mathrm{C}$. On the next day, after the removal of the supernatants, the remaining cells were washed with the co-culture medium three times and then observed under a phase-contrast microscope.

\section{Knockdown of Rat Genes of RECs}

RECs were seeded in 6-cm dishes $\left(2 \times 10^{5} /\right.$ dish $)$ and incubated overnight at $37^{\circ} \mathrm{C}$. On the next day, the culture medium was replaced with serum-free 2-ME-free RPMI 1640 medium. Thereafter, siRNA for rat CD1d or rat SCP2 or negative control siRNA (Life Technologies, Tokyo, Japan) was transfected into RECs using siGENE (Life Technologies) in accordance with the manufacturer's instruction. Forty-eight hours after the siRNA transfection, total RNA was extracted from RECs using an RNeasy Mini kit (Qiagen, Alameda, CA). RNA underwent reverse transcription to cDNA using transcriptase and oligo-dT primers (Promega, Tokyo, Japan). The primers for rat genes used in this study were CD1d sense: $5^{\prime}$-TAGAAGCAGGGAAGCCAGACC-3', CD1d antisense: $\quad 5^{\prime}$-TCCGCATTTGGCAGGATGTC-3', SCP2 sense: 5'-CTTCACGATTGCTTCTCTACC-3', SCP2 antisense: $5^{\prime}$-CAGTGCTCCACCTTGTCCTTC-3', glyceraldehyde-3-phosphate dehydrogenase (GAPDH) sense: $5^{\prime}$ ATGGGAGTTGCTGTTGAAGTCA- ${ }^{\prime}$, and GAPDH antisense: $5^{\prime}$-CCGAGGGCCCACTAAAGG-3'. Real-time PCR was run as follows: after denaturation at $94^{\circ} \mathrm{C}$ for 2 minutes, 40 cycles of reaction at $94^{\circ} \mathrm{C}$ for 15 seconds and at $62^{\circ} \mathrm{C}$ for 60 seconds were performed using the GoTaq 2-Step RTqPCR System (Promega).
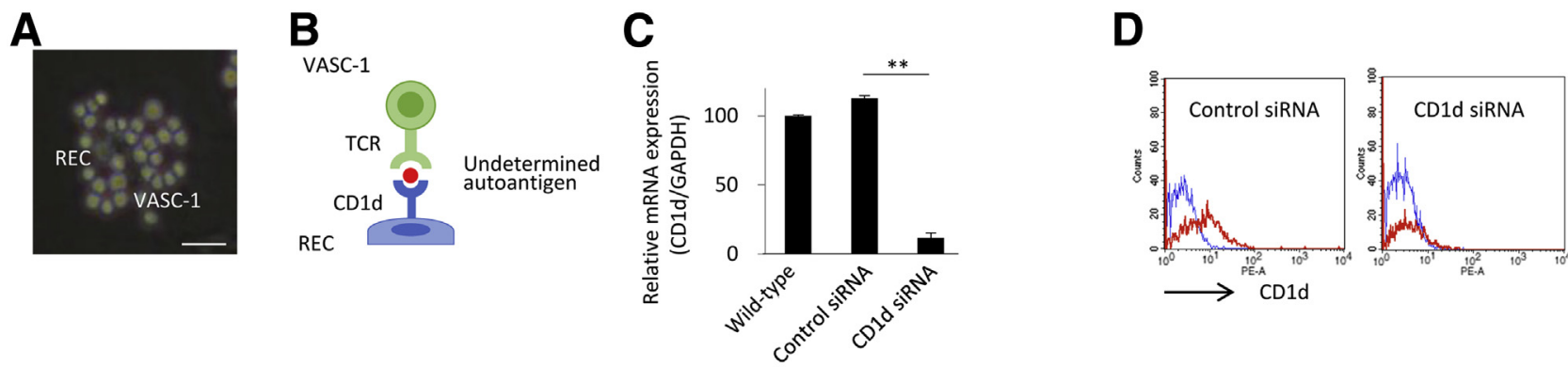

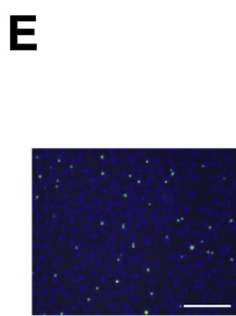

Wild-type

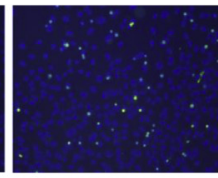

Control antibody

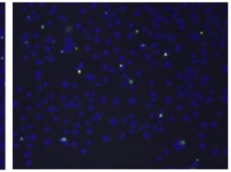

CD1d antibody

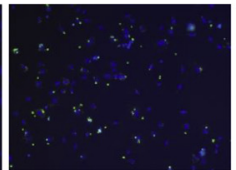

Control siRNA

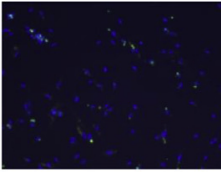

CD1d siRNA

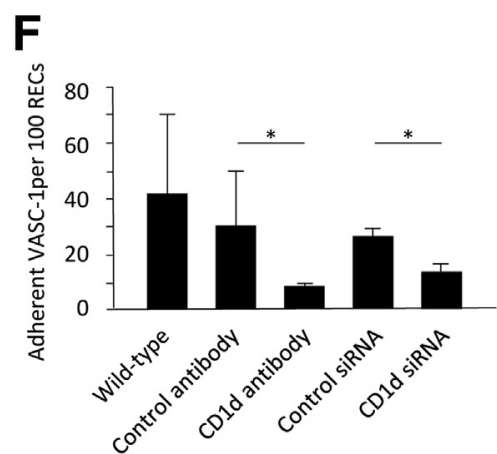

Figure 1 Involvement of CD1d on rat inferior vena cava-derived vascular endothelial cells (RECs) in vascular endothelial cell-reactive T-cell clone (VASC-1) binding. A and B: Representative images of co-cultured VASC-1 with RECs. Knockdown of CD1d of RECs by siRNA at the levels of mRNA (C) and cell surface protein (D). Experiments were performed in triplicate. Decrease in VASC-1 binding to RECs by the inhibition of CD1d using antibody and knockdown of CD1d using siRNA (E and F). Data are expressed as means \pm SD (C and F). $n=3(\mathbf{F})$. ${ }^{*} P<0.05, * * P<0.01$ ( $t$-test). Scale bars: $10 \mu \mathrm{m}(\mathbf{A}) ; 50 \mu \mathrm{m}(\mathbf{E})$. TCR, T-cell receptor. 


\section{Flow Cytometry}

Seventy-two hours after the siRNA transfection, RECs were detached from the dishes and then allowed to react with the anti-mouse/rat CD1d antibody WTH-1 (Abcam, Cambridge, UK) or mouse IgG2a (BD Biosciences, San Jose, CA) was the isotype control on ice for 20 minutes $\left(1 \mu \mathrm{g}\right.$ per $10^{6}$ cells $)$. After washing, the cells were then made to react with 1:2000 diluted phycoerythrin-conjugated donkey anti-mouse $\mathrm{IgG}$ antibody (eBioscience, San Diego, CA) on ice for $30 \mathrm{mi}-$ nutes. Flow cytometry was conducted using FACSCanto II (BD Biosciences), and the data were analyzed using CellQuest Pro software version 6.0 (BD Biosciences).

\section{VASC-1 Binding to RECS or REC Knockdown of CD1d}

Twenty-four hours before this experiment, the medium of VASC-1 was replaced with a fresh one without IL-2. RECs or REC knockdown of CD1d was reseeded in two-well slide chambers $\left(1 \times 10^{5}\right.$ per well $)$ and incubated overnight at $37^{\circ} \mathrm{C}$. On the next day, carboxyfluorescein succinimidyl ester-labeled VASC-1 $\left(2 \times 10^{5}\right.$ per well $)$ was co-cultured with the cells in RPMI 1640 medium containing 20\% FBS and $5 \times 10^{-5} \mathrm{~mol} / \mathrm{L} 2-\mathrm{ME}$ for 2 hours at $37^{\circ} \mathrm{C}$. For reference, a similar co-culture was conducted in the presence of 1 $\mu \mathrm{g} / \mathrm{mL}$ of the anti-CD1d antibody WTH-1. After the removal of the supernatants, the remaining cells were washed with PBS once and then fixed by acetone for 5 minutes at room temperature. The chambers were removed, and then the slide glasses were mounted with VECTASHIELD (Vector Laboratories, Burlingame, CA), which contains DAPI.

\section{Comparison of Amino Acid Sequences of Monkey CD1d and Rat CD1d}

The alignment analysis of amino acid sequences of monkey CD1d (XP_007974824) and rat CD1d (NP_058775) was conducted using Basic Local Alignment Search Tool (BLAST).

\section{Transfection of Rat Genes into COS-7}

COS-7 was grown subconfluently in wells of a six-well plate $\left(1 \times 10^{5}\right.$ per well $)$ at $37^{\circ} \mathrm{C}$. Rat cDNA library derived from the lungs of Sprague-Dawley strain (TKR9543, Takara Bio, Otsu, Japan) was transfected into COS-7 cells using
A

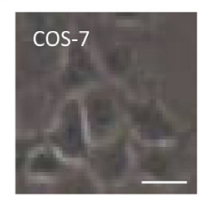

B

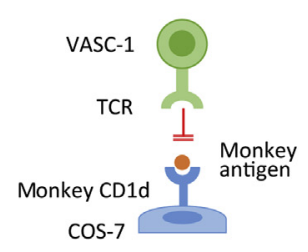

C

monkey LIIWALLOAWGSAEVPORLFPLRCLOISSFANSNWTRTDGLAWLGELOTHSWSNDSDTIR ILIWA $Q W G+E V Q+$ CLQISSFAN +W +RID + WLG+IQIH WSNDSDII rat LLLWAEPQFWGQSEVQQN-YTEGCLQISSFANRSWSRTDSWWLGDLQTHRWSNDSDTIS monkey SLKPWSQGTFSL QQWEALQRVFRVYRSSFTRDVKEFARSL--R_AYPMELQVSAGCEVHP

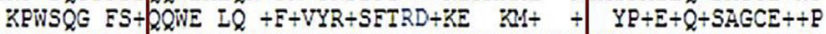
rat FTKPWSQGKESNQQWEKLQHMEQVYRTSFTRDIKEIVRNISPREDYPIEVQLSAGCEMYP

monkey GNASENFFHVAFQGSDILSFQGTSWEPAQEAPI WWNLAIQVLNQDNWIKETVQWLLNDTC GNAS + F EWAEQG ++ F GTSW + EAP $+\div+$ I I ++ IN D I+ETVQ IINDTC

rat GNASESELHVAEQGEYVRRF̈GTSWQKVPEAPAWLDLPIRULNADEGTRETVQILINDTC

monkey PQEVSGLIES|ZKSELEKQVKPKAWLSRGPSPGPGRLQLVCHVSGFYPKPWWVKWIRGEQE PQFV GLIE+EK +LEKQ KP AWLSRGP $+\mathrm{P}$ G LQLVCHVSGE +PRPVWV WURG +QE

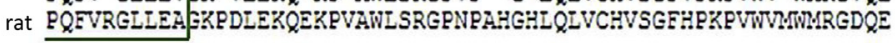

monkey QQGTQRGDILPNADETWYLRATLEVAAGEAAGLSCRVKHSSLEGQDVLYWGGSHTSVGL Q GI RGDILPNADETWYL+ATL+V AG+ AGL+CRVRHSSLEGQDI+IYWGG S I rat QGGTHRGDILPNADETWYLQATLDVEAGDEAGLACRVKHSSLEGDIILYWGGRQVSPVI

monkey IALAVLACLLFLIALIVGETFREKROTSYQGIL

$\mathrm{II}++\mathrm{I}+\mathrm{V} \div \mathrm{KR}+\mathrm{SYO} \mathrm{I}+$

rat IFL--IVGVLVLVWCAVAYYIIRKRRRSYQDIM
Figure 2 Vascular endothelial cell-reactive T-cell clone (VASC-1) binding to COS-7 transfected with the rat gene. $\mathbf{A}$ and $\mathbf{B}$ : Representative images of co-cultured VASC-1 with COS-7. Comparison of amino acid sequences of monkey CD1d (XP_007974824) and rat CD1d (NP_058775) (C). Arg78 and Asp79 in the $\alpha 1$ helix (red box) and Asp152 and Thr155 in the $\alpha 2$ helix (green box), which are critical for antigen presentation to type I natural killer T cells, are identical (blue letters). The plus sign indicates that the amino acids belong to the same amino acid family. Image of co-cultured VASC-1 with COS-7 that has been transfected with rat gene (D). Experimental procedure that identified the COS-7 transfectant with VASC-1 binding, 4D2 (E). IL-5 expression in VASC-1 co-cultured with rat inferior vena cava-derived vascular endothelial cells (RECS) or COS-7 transfectants (F). Total RNA was extracted from VASC-1 that was co-cultured with or without RECs or COS-7 transfectants overnight. 4D2 is the COS-7 transfectant that could bind to VASC-1. Another COS-7 transfectant, 6A4, was used as a control for 4D2. RT-PCR for IL-5 was performed. Glyceraldehyde-3-phosphate dehydrogenase (GAPDH) was used as an internal reference for RNA extraction. Scale bar $=10 \mu \mathrm{m}(\mathbf{A}$ and $\mathbf{E})$. TCR, T-cell receptor.

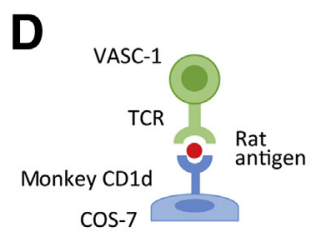

E

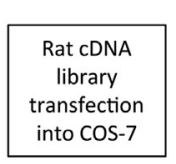

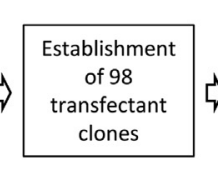
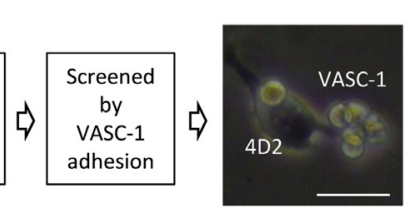

$\mathbf{F}$

$\mathrm{IL}-5$

GAPDH

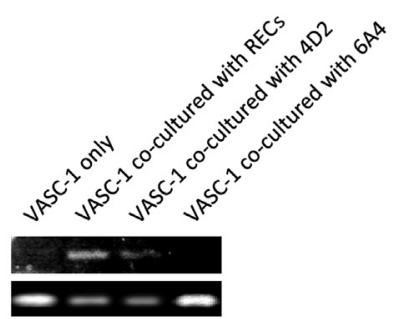


FuGENE (Roche Diagnostics, Tokyo, Japan) in accordance with the manufacturer's instruction. Because the lungs were the most susceptible organs of SVV induced by an i.v. injection of VASC $-1,{ }^{5}$ we used the cDNA library derived from the lungs. This library contains more than $1 \times 10^{6}$ pAP3 neoplasmids carrying diverse rat cDNA fragments in its multiple cloning sites that lie between the T3 and T7 promoters. Seventy-two hours after the transfection, the cells were exposed to $650 \mu \mathrm{g} / \mathrm{mL}$ of G418 in DMEM and cultured further for a week at $37^{\circ} \mathrm{C}$. Live cells were collected, reseeded sparsely (200 cells per 9-cm dish), and cultured in DMEM containing $325 \mu \mathrm{g} / \mathrm{mL}$ of G418 at $37^{\circ} \mathrm{C}$. One week later, colony-forming live cells were picked under a phase-contrast microscope and transferred into wells of 24-well plates. Consequently, 98 COS-7 transfectants were established. These cells were stored at $-150^{\circ} \mathrm{C}$ until use.

\section{Verification of Rat Gene Insertion in COS-7 Transfectants}

DNA was extracted from the aforementioned 98 COS-7 transfectants using a DNeasy Blood and Tissue Mini Kit (Qiagen). The insertion of rat genes was detected by PCR using the $\mathrm{T} 3$ and $\mathrm{T} 7$ promoter primers, which lie at either end of the multiple cloning sites for rat genes. PCR was run using AmpliTaq Gold 360 Master Mix (Applied Biosystems, Yokohama, Kanagawa) as follows: after denaturation at $94^{\circ} \mathrm{C}$ for 2 minutes, 35 cycles of reaction at $94^{\circ} \mathrm{C}$ for 30 seconds, at $55^{\circ} \mathrm{C}$ for 30 seconds, and at $72^{\circ} \mathrm{C}$ for 60 seconds. Electrophoresis of the PCR products through $1 \%$ agarose gel revealed that a single rat gene fragment was inserted in 45 COS-7 transfectants and more than two fragments were inserted in 42 COS-7 transfectants, although no insertion of the rat gene was evident in 11 COS-7 transfectants.

\section{Co-Culture of VASC-1 and COS-7 Transfectants}

Twenty-four hours before this experiment, the medium of VASC-1 was replaced with a fresh one without IL-2. Each COS-7 transfectant that carried a single rat gene fragment $(n=45)$ was grown subconfluently in a well of six-well plates $\left(1 \times 10^{5}\right.$ per well $)$ at $37^{\circ} \mathrm{C}$. VASC- $1\left(2 \times 10^{5}\right.$ per well) was co-cultured with the cells in RPMI 1640 medium containing $20 \% \mathrm{FBS}$ and $5 \times 10^{-5} \mathrm{~mol} / \mathrm{L} 2-\mathrm{ME}$ overnight at $37^{\circ} \mathrm{C}$. On the next day, after the removal of the supernatants, the remaining cells were washed with the co-culture medium three times and then observed under a phasecontrast microscope. A COS-7 transfectant, 4D2, was found to bind VASC-1.

\section{Detection of Cytokine Expression in VASC-1} Co-Cultured with COS-7 Transfectants

After an overnight co-culture with the COS-7 transfectant, $4 \mathrm{D} 2$, according to the same protocol as above, total RNA

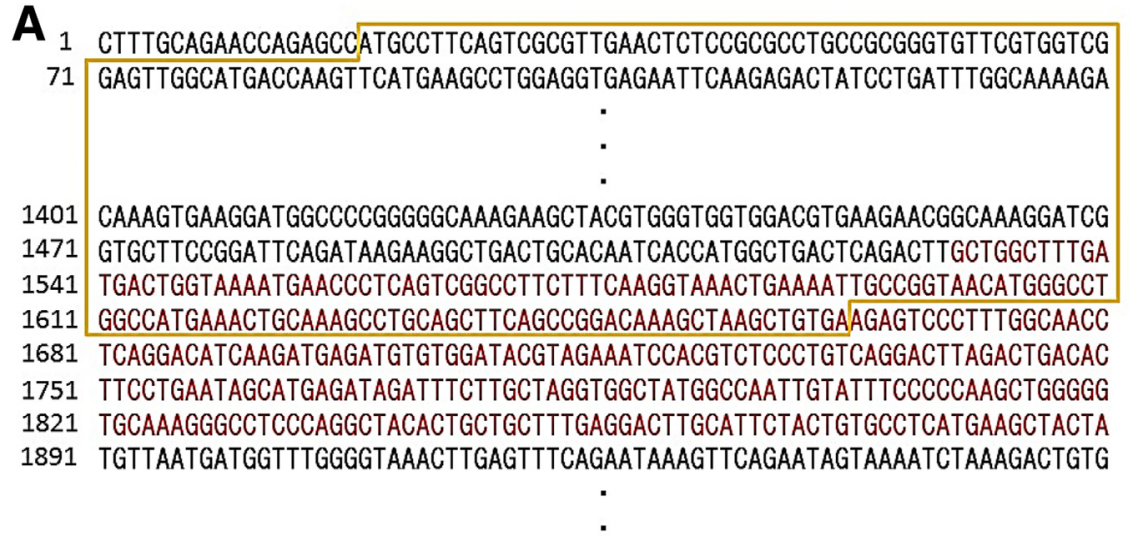

2451 GTTGTCTGCATTTATCTTTCTTCCTGGTTTTTCTAACTCTAACGCTGTTTGTTATAATTTAGGTTTGGGA 2521 TAAAAATATGCTTTTGGAAGATTTAAAAAGAAAATTAAAACAGCTCTTCCT

B

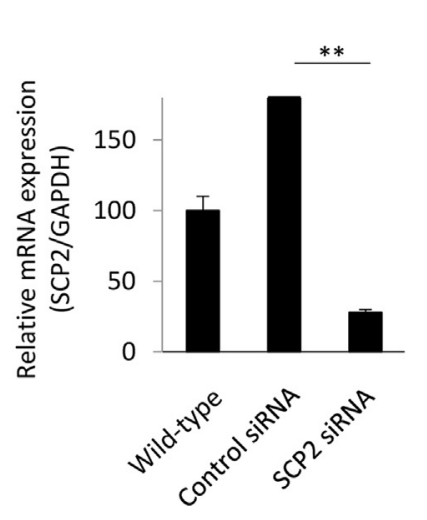

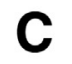

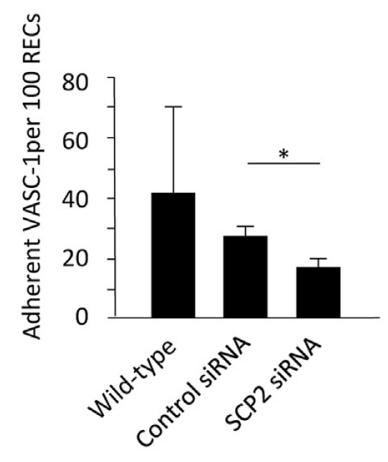

Figure 3 Involvement of sterol carrier protein 2 (SCP2) of rat inferior vena cava-derived vascular endothelial cells (RECS) in vascular endothelial cell-reactive T-cell clone (VASC-1) binding. A: Rat SCP2 CDNA. The yellow box indicates the open reading flame. The $3^{\prime}$-flanking fragment in red letters had been introduced into 4D2. Effects of SCP2 knockdown of RECS on SCP2 mRNA expression (B) and VASC-1 binding (C). Data are expressed as means \pm SD (B and $\mathbf{C}) . n=3(\mathbf{C}) .{ }^{*} P<0.05$, ${ }^{* *} P<0.01$ (t-test). GAPDH, glyceraldehyde-3phosphate dehydrogenase; TCR, T-cell receptor. 
was extracted from VASC-1 using an RNeasy Mini kit. RNA underwent reverse transcription to cDNA using transcriptase and oligo-dT primers. The primers for rat genes used in this study were IL-5 sense: 5'-GACGAGCAATGAGACGATGAGGCT-3', IL-5 antisense: 5'-ACAGTGCCCCCTCGGACAGTT- $3^{\prime}$, and the former GAPDH sense and GAPDH antisense. PCR was run using AmpliTaq Gold 360 Master Mix as follows: after denaturation at $94^{\circ} \mathrm{C}$ for 30 seconds, 35 cycles of reaction at $58^{\circ} \mathrm{C}$ for 30 seconds and at $72^{\circ} \mathrm{C}$ for 30 seconds. For the positive and negative controls, VASC-1 was co-cultured with RECs and with another COS7 transfectant, $6 \mathrm{~A} 4$, respectively.

\section{Identification of the Rat Gene Transfected into 4D2}

DNA was extracted from the COS-7 transfectant, 4D2, which could bind to VASC-1, using the DNeasy Blood and Tissue Mini Kit (Qiagen). The transfected rat gene via the pAP3 neoplasmid was amplified by PCR using the T3 and T7 promoter primers, and then the PCR product was sequenced directly using GenomeLab Dye Terminator Cycle Sequencing with Quick Start Kit (Beckman Coulter, Tokyo, Japan). Consequently, the rat gene transfected into 4D2 was identified to code SCP2.
VASC-1 Binding to RECS or REC Knockdown of SCP2

This assay was performed similarly to the assay for VASC-1 binding to REC knockdown of CD1d.

\section{Transduction of SCP2 Peptides into COS-7}

According to the sequence transfected into 4D2, 26 series of SCP2 peptides were designed. The amino acid sequences and expected hydropathy indexes ${ }^{18}$ are listed in Table 1. The greater the index is, the more hydrophobic the amino acid becomes. Because CD1d expressed preferably hydrophobic peptides, we requested Thermo Fisher Scientific (Osaka, Japan) to generate the nine peptides with a hydropathy index $>0.200$ (Table 1). The BioPORTER Protein Delivery Reagent (Genlantis, Tokyo, Japan) was applied for the intracellular delivery of SCP2 peptides according to the manufacturer's instruction. In brief, COS-7 was seeded in two-well slide chambers $\left(1 \times 10^{5}\right.$ per well $)$ and incubated overnight at $37^{\circ} \mathrm{C}$. SCP2 peptides were diluted in PBS $(4 \mu \mathrm{g} / 40 \mu \mathrm{L}$ ), and then BioPORTER-coated tubes were hydrated with the SCP2 peptide solution and diluted to 500 $\mu \mathrm{L}$ with serum-free DMEM. The total volume of BioPORTER/SCP2 peptide complexes was transferred onto

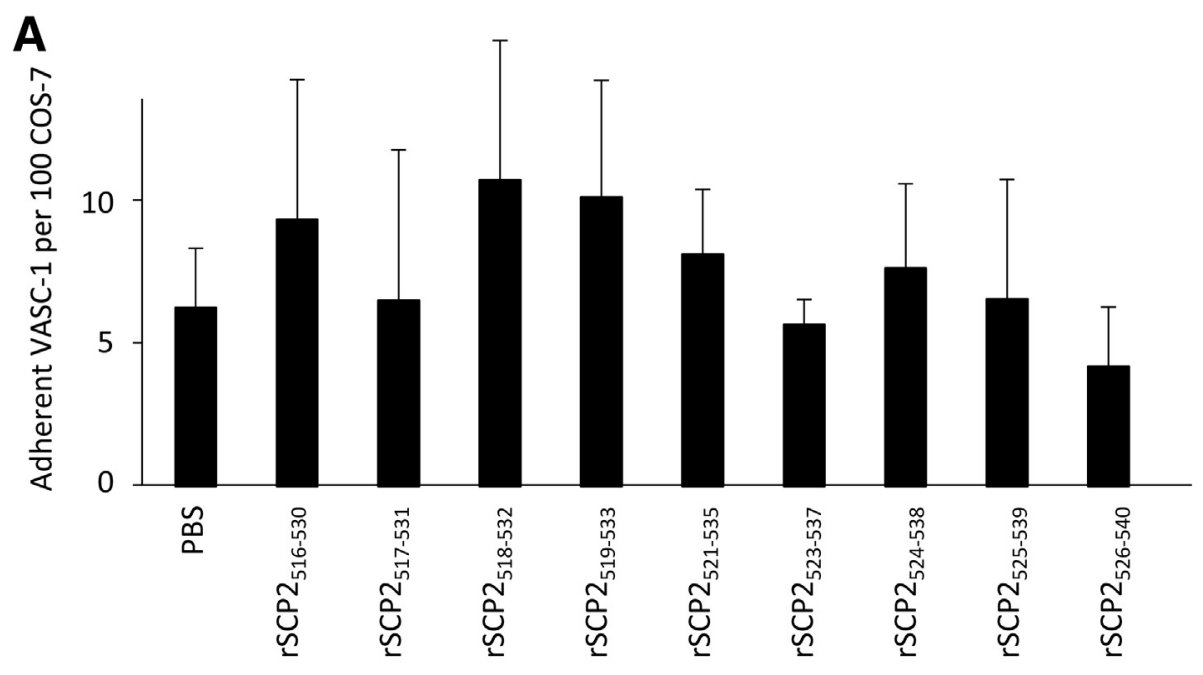

Figure 4 Screening of sterol carrier protein 2 (SCP2) peptide recognized by vascular endothelial cell-reactive T-cell clone (VASC-1). A: Screening of nine SCP2 peptides for the induction of VASC-1 binding to COS-7. B and C: Adherent VASC-1 per 100 COS-7 values were calculated from six random fields of view. VASC-1 binding was increased by

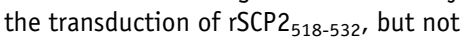
rSCP2 2526-540, into COS-7. Data are expressed as means \pm SEM (A and $\mathbf{C}$ ). $n=3$ (C). ${ }^{*} P<0.05$ (t-test). Scale bar $=50 \mu \mathrm{m}$ (B). PBS, phosphatebuffered saline.

B

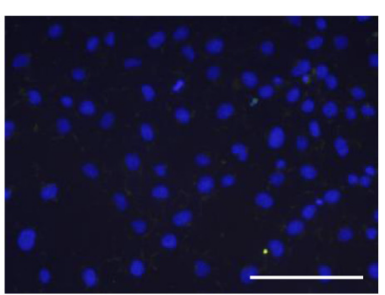

PBS

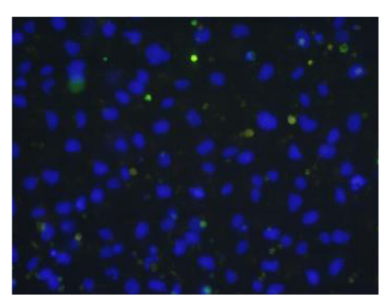

$\mathrm{rSCP} 2_{518-532}$

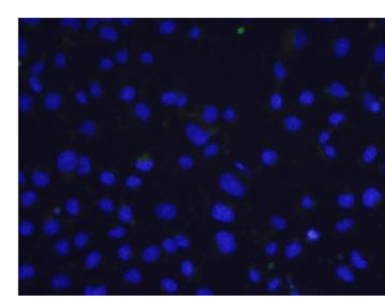

$\mathrm{rSCP}_{526-540}$
C

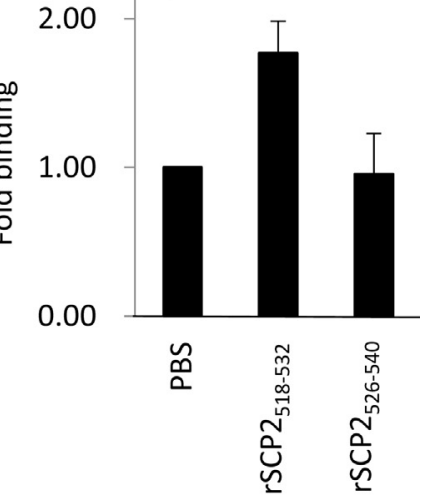


COS-7 cells after being washed with serum-free DMEM, and then these cells were incubated in the culture medium for 5 hours at $37^{\circ} \mathrm{C}$.

\section{VASC-1 Binding to COS-7 or COS-7 Transduced SCP2 Peptides}

This assay was performed similarly to the assay for VASC-1 binding to RECs.

\section{VASC-1 Proliferation Assay}

Twenty-four hours before this experiment, the culture medium of VASC-1 was replaced with RPMI 1640 medium devoid of FBS, 2-ME, and rat IL-2. The knockdown for the SCP2 gene of RECs was conducted as aforementioned. In some wells of REC knockdown of $S C P 2$, SCP2 peptides (rSCP2 ${ }_{518-532}$ and rSCP2 $256-540$ ) were transduced into the cells similarly to the transduction into COS-7. Thereafter, these cells were washed with PBS twice. VASC-1 $\left(4 \times 10^{5}\right.$ per well $)$ was co-cultured with the cells for 2 hours at $37^{\circ} \mathrm{C}$. Finally, the supernatants $(90$ $\mu \mathrm{L})$ were transferred into wells of a 96-well plate. Ten microliters of AlamarBlue (Thermo Fisher Scientific) were added to each well and incubated for 2 hours at $37^{\circ} \mathrm{C}$. Thereafter, the absorbance at $570 \mathrm{~nm}$ was measured, and VASC-1 proliferation was calculated as follows: Proliferation $(\%)=($ Sample Well - Blank Well $) \times 100 /($ Control Well - Blank Well).

\section{Immunization of Rats}

$\mathrm{SCP} 2$ peptide solution ( $\mathrm{rSCP} 2_{518-532}$ or $\mathrm{rSCP} 2_{526-540}, 400$ $\mu \mathrm{g} / \mathrm{mL}$ in dimethyl sulfoxide) was mixed with an equal volume of Freund's complete adjuvant. The emulsion was injected into the skin on the back of premorbid young disease-prone rats (5-week-old male, $100 \mu \mathrm{L}$ per site $\times 5$ sites per rat). Ten days later, the emulsion that contained SCP2 peptide and Freund's incomplete adjuvant was prepared and then injected similarly as the first immunization. Four days later, all rats were euthanized for histologic examination. Six rats were used for $\mathrm{rSCP} 2_{518-532}$ immunization, and seven rats were used for $\mathrm{rSCP} 2_{526-540}$ immunization.

\section{Histologic Examination}

The systemic organs of rats, including the cerebrum, cerebellum, thymus, heart, lungs, liver, spleen, pancreas, kidneys, adrenal glands, testis, skin, muscle, salivary glands, and lymph nodes, were processed for tissue sections with hematoxylin and eosin staining, Masson trichrome staining, and immunohistochemistry for $\alpha$-smooth muscle actin ( $\alpha$-SMA). Immunohistochemistry for $\alpha$-SMA was performed using the anti-human $\alpha$-SMA antibody (1A4) and LSAB2 kit, universal (Dako, Tokyo, Japan). Briefly, after antigen retrieval by heat mediation $\left(121^{\circ} \mathrm{C}, 15\right.$ minutes), consumption of the endogenous peroxidase activity by exposure to $3 \% \mathrm{H}_{2} \mathrm{O}_{2}$, and inhibition of nonspecific binding by exposure to the blocking buffer in the kit, the sections were incubated with 1:100 diluted $1 \mathrm{~A} 4$ for 30 minutes at room temperature. After removal of unbound antibodies, the sections were next allowed to react with the biotin-conjugated secondary antibody in the kit for 1 hour at room temperature, followed by development of color according to the kit protocol. The histologic score of SVV was determined according to the number of organs with vasculitic lesions ( 0 for no organ with
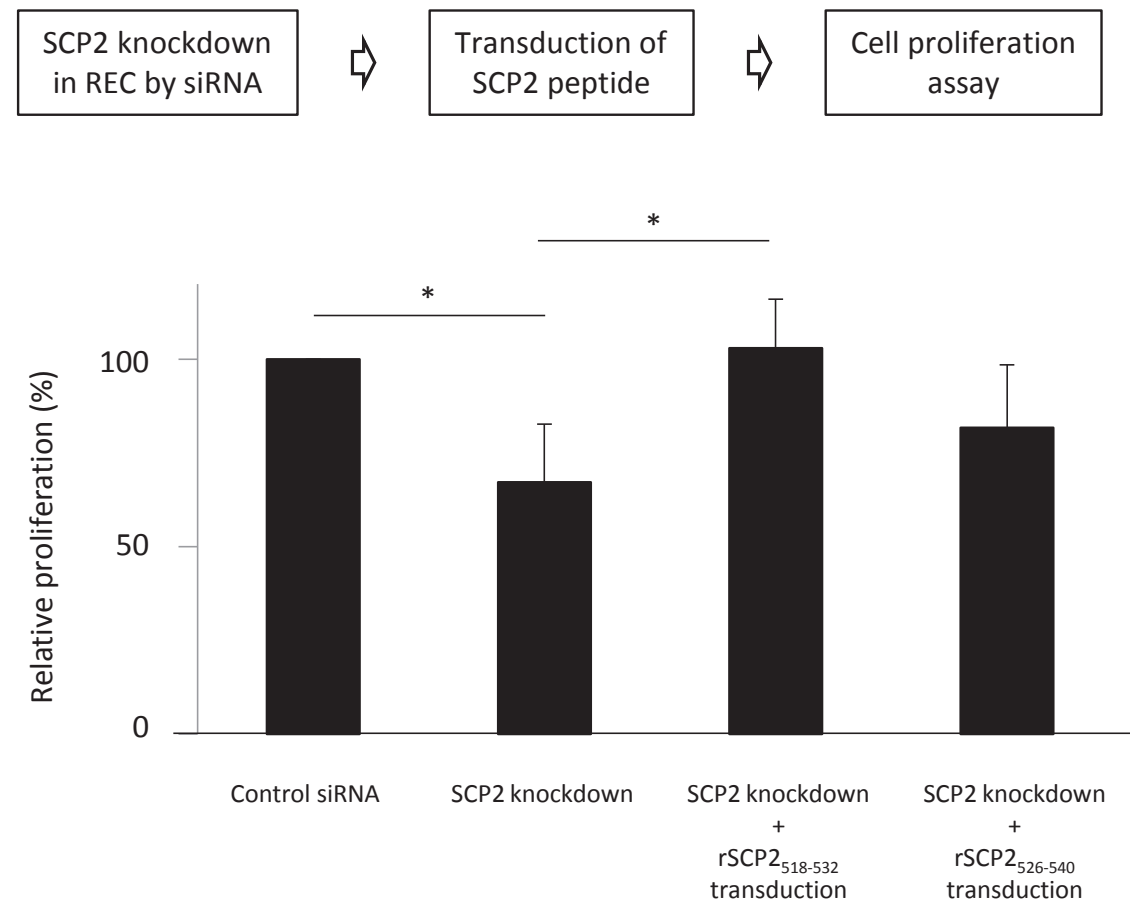

Figure 5 Identification of $\mathrm{rSCP} 2_{518-532}$ as the epitope recognized by vascular endothelial cellreactive T-cell clone (VASC-1). The proliferation of VASC-1 that interacted with rat inferior vena cava-derived vascular endothelial cells (RECS) was decreased when sterol carrier protein 2 (SCP2) of RECs had been knocked down. However, the decrease was canceled by the transduction of

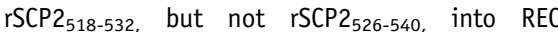
knockdown of SCP2. Data are expressed as means \pm SD. $n=3 .{ }^{*} P<0.05$ ( $t$-test). 
lesions; 1, 2, and 3 for one, two, and three organs with lesions; and 4 for four or more organs with lesions).

\section{Statistical Analysis}

The $t$-test was applied for comparison of the mean values between the two in vitro groups. The Mann-Whitney $U$-test was applied for comparison of the two in vivo groups. $P<0.05$ was regarded as statistically significant.

\section{Results}

\section{Involvement of CD1d on RECs in VASC-1 Binding}

When VASC-1 was co-cultured with RECs, VASC-1 became bound to RECs (Figure 1A). The results of our previous study suggest that RECs present a certain autoantigen on CD1d, and VASC-1 recognizes the autoantigen via TCR (Figure 1B). ${ }^{5}$ To confirm the involvement of CD1d on RECs in VASC-1 binding, we attempted to knock down CD1d of RECs by siRNA. At first, we determined whether siRNA could exactly knock down CD1d of RECs using real-time RT-PCR and flow cytometry. As a result, both mRNA and cell surface expression of CD1d were markedly reduced in RECs transfected with siRNA for CD1d (Figure 1, C and D). Next, VASC-1 was co-cultured with RECs in the presence of anti-CD1d antibody or with REC knockdown of CD1d. As a result, the quantity of VASC-1 bound to RECs was significantly reduced by both the inhibition and knockdown of CD1d (Figure 1, E and F). These findings confirmed the involvement of CD1d on RECs in VASC-1 binding.

\section{VASC-1 Binding to COS-7 Transfected with the Rat Gene}

Naturally, VASC-1 does not bind to monkey-derived COS7 (Figure 2A). It seems likely that the TCR of VASC-1 cannot recognize monkey antigens presented by monkey CD1d (Figure 2B). However, it is known that CD1d molecules are well conserved among species. For instance, Arg78 and Asp79 in the $\alpha 1$ helix and Asp152 and Thr155 in the $\alpha 2$ helix, which are critical for antigen presentation to type I NKT cells, ${ }^{19}$ are identical between monkey CD1d and rat CD1d (Figure 2C). Therefore, we hypothesized that VASC- 1 could bind to COS-7 if the monkey CD1d would present rat antigens (Figure 2D). To verify the hypothesis, rat cDNA library $\left(1 \times 10^{6}\right.$ diversity $)$ was transfected into COS-7, and consequently, 98 COS-7 transfectants carrying various rat genes were established. By screening for VASC1 binding under the co-culture condition, a COS-7 transfectant, named 4D2, was found to bind to VASC-1 (Figure 2E). Furthermore, VASC-1 co-cultured with the COS-7 transfectant 4D2, which could bind to VASC-1, was able to express IL-5; this was also the case when VASC-1 was co-cultured with RECs (Figure 2F). On the contrary, no expression of IL-5 was observed in VASC-1 that was co-cultured with another COS-7 transfectant, 6A4. Because IL-5 expression was mediated by CD1d-dependent stimulation via TCR, ${ }^{5}$ the collective findings suggested that the TCR of VASC-1 could cross-react with monkey CD1d when an appropriate rat antigen was presented.

\section{Identification of the Rat Gene Transfected into 4D2}

DNA sequencing identified that the rat gene transfected into 4D2 was a $3^{\prime}$-flanking fragment of the gene coding an intracellular lipid transfer molecule, SCP2 (Figure 3A). The C-terminal open reading frame of $\mathrm{SCP} 2$ was included in the fragment.

\section{Involvement of SCP2 in VASC-1 Binding to RECS}

To determine whether SCP2 could really be involved in VASC-1 binding to RECs, SCP2 of RECs was knocked down by siRNA. When we examined the mRNA expression of

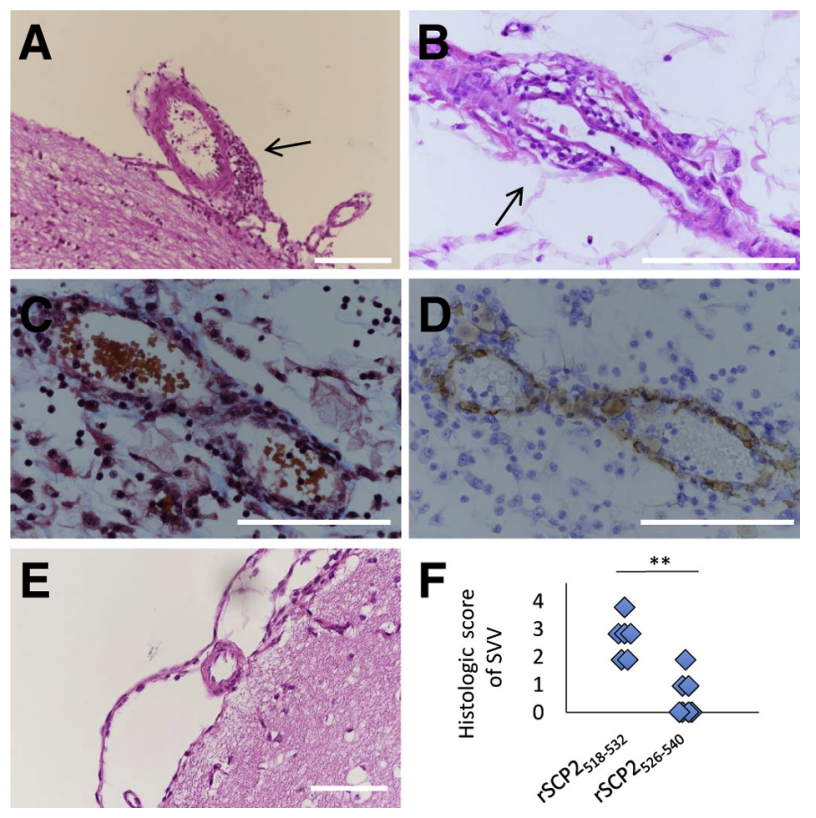

Figure 6 Accelerated development of small-vessel vasculitis (SVV) by immunization with $\mathrm{rSCP}_{518-532}$. Premorbid young disease-prone rats (5-week-old males) were immunized with rSCP2 $2_{518-532}$ or $\mathrm{rSCP} 2_{526-540}$. Two weeks later, histologic examination was conducted. All rats immunized with rSCP2 ${ }_{518-532}$ ( 6 out of 6 ) developed SVV at 7 weeks old. A: Section of cerebrum with hematoxylin and eosin (H\&E) staining. B-D: Sections of skin with HE staining (B), Masson's trichrome staining (C), and $\alpha$-smooth muscle actin immunostaining (D). Arrows in $\mathbf{A}$ and $\mathbf{B}$ indicate inflammatory cell infiltration into the small vessel wall and perivascular infiltration of inflammatory cells. Few vasculitic lesions were observed in rats immunized with the control peptide, $\mathrm{rSCP}_{526-540}(\mathbf{E}$, no vasculitic change in the small vessel corresponding to A). F: Comparison of the histologic score according to the number of organs with vasculitic lesions between rats immunized with $\mathrm{rSCP}_{518-532}$ and rats immunized with the control peptide, rSCP2 $526-540 . n=6$ rats immunized with $\mathrm{rSCP}_{518-532 ;} n=7$ rats immunized with rSCP2 $526-540 .{ }^{*} P<0.01$ (U-test). Scale bars $=200 \mu \mathrm{m}(\mathbf{A}-\mathbf{E})$. Original magnification: $\times 200(A$ and $E) ; \times 400(B-D)$. 
SCP2 of RECs transfected with siRNA for SCP2, the expression was markedly reduced (Figure $3 \mathrm{~B}$ ). Correspondingly, VASC-1 binding to RECs was decreased significantly by the knockdown of SCP2 (Figure 3C). These findings suggest the involvement of SCP2 in VASC-1 binding to RECs.

\section{Identification of SCP2 Epitope Recognized by VASC-1}

On the basis of the $S C P 2$ gene sequence that had been transfected into $4 \mathrm{D} 2$, we designed 26 series of SCP2 peptides (Table 1). Because CD1d expressed preferably hydrophobic peptides, the nine peptides with a hydropathy index $>0.200$ (Table 1) were selected to be generated. To identify the epitope of SCP2 recognized by VASC-1, the nine peptides were transduced into COS-7, and then VASC1 binding was screened. It is conceivable that cell surface CD1d molecules have been occupied by putative antigens. Thus, we used the transfection procedure to express the SCP2 peptides on CD1d. We also determined that the addition of SCP2 peptides in the culture medium could not increase the VASC-1 proliferation co-cultured with REC knockdown of SCP2 (data not shown). As a result, transduction of rSCP2 ${ }_{518-532}$ induced the highest binding of VASC-1 to COS-7 (Figure 4A). On the contrary, transduction of rSCP2 $2_{526-540}$ did not promote VASC-1 binding to COS-7 at all. Repeated experiments using rSCP2 $2_{518-532}$ and rSCP2 ${ }_{526-540}$ reproduced similar results (Figure 4, B and C).

Moreover, we found that REC-dependent proliferation of VASC-1 was decreased significantly when SCP2 of RECs had been knocked down by siRNA and that the decrease could be canceled by the transduction of $\mathrm{rSCP} 2_{518-532}$ but not rSCP2 $526-540$ (Figure 5). The collective findings suggest that $\mathrm{rSCP} 2_{518-532}$ includes the epitope recognized by VASC-1.

Accelerated Development of SVV by Immunization with rSCP2 $518-532$

Next, we determined whether immunization with rSCP2 ${ }_{518-532}$ could promote the development of SVV. For this purpose, premorbid young disease-prone rats were used. Although SVV usually develops in rats $>2$ months old, ${ }^{1,20}$ all rats immunized with $\mathrm{rSCP} 2_{518-532}(n=6 / 6)$ developed SVV at 7 weeks old (Figure 6, A-D). The histologic scores

\section{Autoreactive type II NKT cells}

\section{(Nonvasculitic condition)}

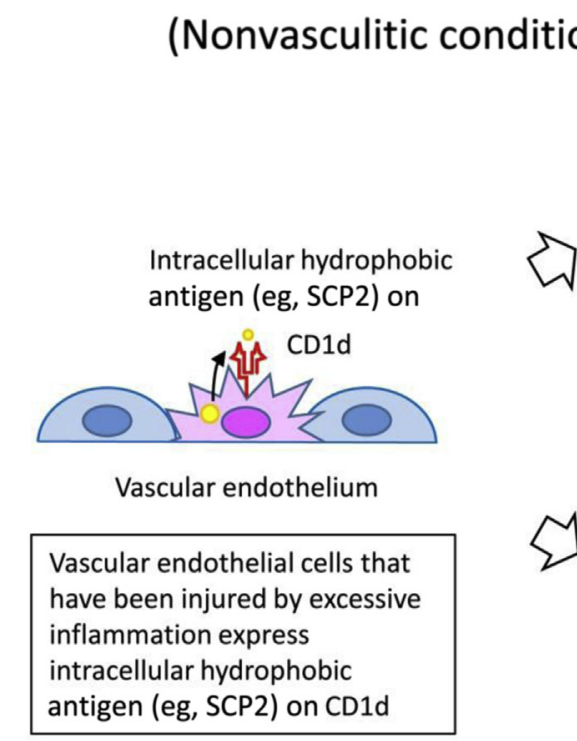

(Vasculitic condition)
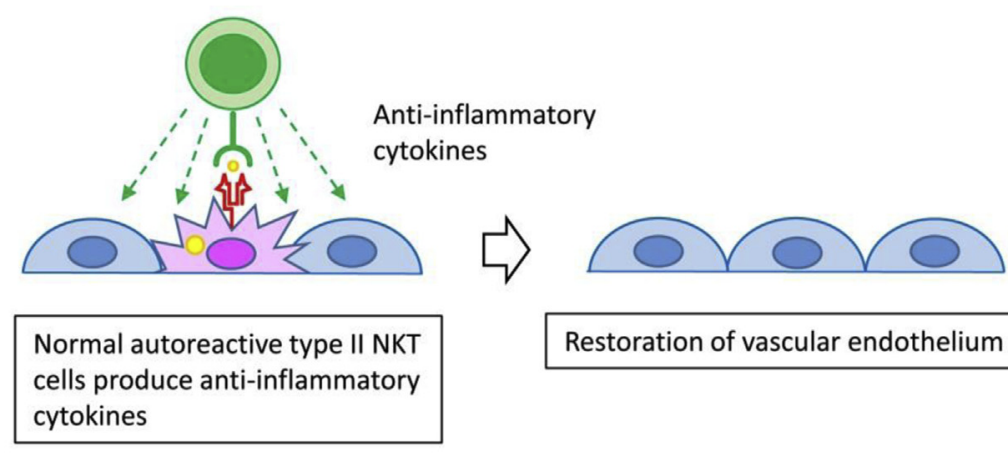

Restoration of vascular endothelium
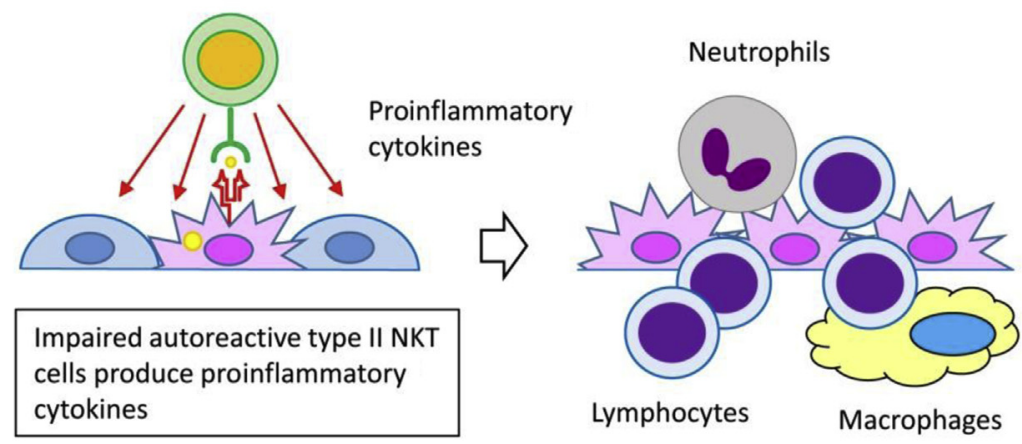

Development of SVV

Figure 7 Schematic diagram of the disease mechanism implicated in vascular inflammation in the rat model. Excessive inflammation sometimes results in injury of vascular endothelial cells. Under such a situation, the injured vascular endothelial cells present intracellular hydrophobic autoantigens [eg, sterol carrier protein 2 (SCP2)] on CD1d to activate type II natural killer T (NKT) cells. Thereafter, the activated type II NKT cells function to converge inflammation by producing anti-inflammatory cytokines in a nonvasculitic condition. However, the impaired type II NKT cells cannot prevent the spread of inflammation but rather enhance the vascular inflammation by producing proinflammatory cytokines. 
according to the number of organs with vasculitic lesions were significantly higher in rats immunized with rSCP2 $2_{518-532}$ than in those immunized with the control peptide, rSCP2 ${ }_{526-540}$ (Figure 6, E and F). These results indicate that $\mathrm{rSCP} 2_{518-532}$-reactive cells, including type II NKT cells, are critically implicated in the development of vascular inflammation in the rat model.

\section{Discussion}

In the present study, we found that the rat type II NKT cell clone, VASC-1, can recognize SCP2 peptides presented by CD1d. CD1d is known as a class I major histocompatibility complex-like antigen-presenting molecule that prefers to present hydrophobic antigens, including bacterial glycolipids. ${ }^{6}$ Although recent studies have revealed that sulfatides and peptides can be also presented by CD1d, ${ }^{14,15,21}$ the hydrophobicity of CD1d is a primary characteristic based on the molecular structure.

SCP2 is a $13-\mathrm{kDa}$ protein that is implicated in intracellular lipid transfer. ${ }^{22}$ The N-terminal 32 amino acids of SCP2 form an amphipathic $\alpha$-helix domain, which functions as a lipid carrier and a ligand-binding region simultaneously. On the contrary, the hydrophobic surface of the $\alpha$ helix constitutes a hollow structure with $\beta$-strands in the SCP2 molecule. This hollow structure binds to phospholipids.

The SCP2 gene fragment that had been transduced in the COS-7 transfectant with VASC-1 binding, 4D2, lacked the translation initiation codon for the complete SCP2 molecule. However, it contained some in-frame codons coding methionine, which could initiate the subsequent translation into certain fragmented proteins, including a part of the $\beta$-strands of the SCP2 molecule. It is conceivable that the SCP2 fragments expressed in 4D2 are hydrophobic in terms of the expected binding to phospholipids. Therefore, it is reasonable to consider that the SCP2 peptides can be presented by CD1d in 4D2. Moreover, this study has revealed that the SCP2 epitope recognized by VASC-1 is present in $\mathrm{rSCP} 2_{518-532}$. This peptide is the most hydrophobic among the 26 candidate peptides; hence, it is consistent with the hydrophobicity of CD1d.

More recently, Girardi et $\mathrm{al}^{23}$ reviewed that peptides, which included the [FW]-X-X-[ILM]-X-X-W motif, could bind to mouse CD1d. Although rSCP2 ${ }_{518-532}$ does not include the CD1d-binding motif, another CD1d-binding peptide, mCII $_{707-721},{ }^{16}$ does not include the motif either. We considered that diverse antigens could be presented by CD1d.

We do not have any evidence to conclude that the SCP2 peptide is the sole autologous antigen presented by CD1d. Because the CD1d molecule can present diverse kinds of antigens, such as glycolipids, sulfatides, and peptides, regardless of the presence of the [FW]-X-X-[ILM]-X-X-W motif, it seems likely that several peptides derived from intracellular proteins, if hydrophobic, can be presented by CD1d. We were probably able to isolate an NKT cell clone that recognized the SCP2 peptide by chance.

The expression of SCP2 is distributed widely in the lipid metabolism-related organs and cells, including the liver and vascular endothelial cells. ${ }^{24}$ Although SCP2 is associated with the pathogenesis of arteriosclerosis, ${ }^{25}$ the association between SCP2 and vasculitides remains unrevealed. Further studies are needed to clarify the role of SCP2 in the pathogenesis of vasculitides.

Accumulated studies have revealed the immunoregulatory properties of type II NKT cells in the immune reaction. Liu et $\mathrm{al}^{16}$ found that NKT cells reactive with autologous peptides (suggestive of type II phenotype) exhibited an immunosuppressive property in healthy mice. Correspondingly, the activation of type II NKT cells ameliorated the murine experimental hepatitis. ${ }^{26-28}$ Furthermore, Terabe et $\mathrm{al}^{29}$ found that type II NKT cells were essential for the down-regulation of tumor immunosurveillance in wild-type mice. On the contrary, the association of the disorder of type II NKT cells with inflammatory diseases is also reported. Liao et $\mathrm{al}^{30}$ found that the disordered regulation of type II NKT cells could cause a spontaneous development of colitis in CD1d transgenic mice. In summary, type II NKT cells belong to the immunoregulatory $\mathrm{T}$ cells, and the disorder of these cells can be implicated in immune-related inflammatory diseases. In our previous study, the type II NKT cell clone, VASC-1, had proinflammatory but not antiinflammatory properties when made to react with autologous vascular endothelial cells. ${ }^{5}$

In conclusion, the collective evidence suggests that a disordered immunoregulatory function of autoreactive type II NKT cells can be implicated in the development of vascular inflammation in the rat model. The impairment of vascular endothelial cell-reactive type II NKT cells with an immunoregulatory property could be implicated in the pathogenic modification of diverse human vasculitides, in which vascular endothelial cells are injured by inflammation (Figure 7). Although a full comprehension of the pathogenesis of vasculitides remains far off, this study can be a stream of light that illuminates the pathway.

\section{References}

1. Yamazaki H, Ikeda H, Ishizu A, Nakamaru Y, Sugaya T, Kikuchi K, Yamada S, Wakisaka A, Kasai N, Koike T, Hatanaka M, Yoshiki T: A wide spectrum of collagen vascular and autoimmune diseases in transgenic rats carrying the env-pX gene of human T lymphocyte virus type I. Int Immunol 1997, 9:339-346

2. Nakamaru Y, Ishizu A, Ikeda H, Sugaya T, Fugo K, Higuchi M, Yamazaki H, Yoshiki T: Immunological hyperresponsiveness in HTLV-I LTR-env-pX transgenic rats: a prototype animal model for collagen vascular and HTLV-I-related inflammatory diseases. Pathobiology 2001, 69:11-18

3. Fugo K, Ishizu A, Ikeda H, Hayase H, Sugaya T, Higuchi M, Tsuji M, Abe A, Suzuki A, Shibata M, Takahashi T, Yoshiki T: The role of the thymus in development of necrotizing arteritis in transgenic rats 
carrying the env-pX gene of human T-cell leukemia virus type-I. Am J Pathol 2002, 161:755-761

4. Higuchi M, Ishizu A, Ikeda H, Hayase H, Fugo K, Tsuji M, Abe A, Sugaya T, Suzuki A, Takahashi T, Koike T, Yoshiki T: Functional alteration of peripheral $\mathrm{CD} 25^{+} \mathrm{CD} 4^{+}$immunoregulatory $\mathrm{T}$ cells in a transgenic rat model of autoimmune diseases. J Autoimmun 2003, 20 : 43-49

5. Iinuma C, Waki M, Kawakami A, Yamaguchi M, Tomaru U, Sasaki N, Masuda S, Matsui Y, Iwasaki S, Baba T, Kasahara M, Yoshiki T, Paletta D, Herrmann T, Ishizu A: Establishment of a vascular endothelial cell-reactive type II NKT cell clone from a rat model of autoimmune vasculitis. Int Immunol 2015, 27:105-114

6. Wu L, Gabriel CL, Parekh VV, Van Kaer L: Invariant natural killer T cells: innate-like $\mathrm{T}$ cells with potent immunomodulatory activities. Tissue Antigens 2009, 73:535-545

7. Girardi E, Zajonc DM: Molecular basis of lipid antigen presentation by CD1d and recognition by natural killer T cells. Immunol Rev 2012, 250:167-179

8. Rossjohn J, Pellicci DG, Patel O, Gapin L, Godfrey DI: Recognition of CD1d-restricted antigens by natural killer T cells. Nat Rev Immunol 2012, 12:845-857

9. Godfrey DI, MacDonald HR, Kronenberg M, Smyth MJ, Van Kaer L: NKT cells: what's in a name? Nat Rev Immunol 2004, 4: 231-237

10. Macho-Fernandez E, Brigl M: The Extended Family of CD1dRestricted NKT Cells: sifting through a Mixed Bag of TCRs, Antigens, and Functions. Front Immunol 2015, 6:362

11. Matsuura A, Kinebuchi M, Chen HZ, Katabami S, Shimizu T, Hashimoto Y, Kikuchi K, Sato N: NKT cells in the rat: organ-specific distribution of NK T cells expressing distinct $\mathrm{V} \alpha 14$ chains. J Immunol 2000, 164:3140-3148

12. Godfrey DI, Stankovic S, Baxter AG: Raising the NKT cell family. Nat Immunol 2010, 11:197-206

13. Monzon-Casanova E, Paletta D, Starick L, Muller I, Sant'Angelo DB, Pyz E, Herrmann T: Direct identification of rat iNKT cells reveals remarkable similarities to human iNKT cells and a profound deficiency in LEW rats. Eur J Immunol 2013, 43:404-415

14. Girardi E, Maricic I, Wang J, Mac TT, Iyer P, Kumar V, Zajonc DM: Type II natural killer $\mathrm{T}$ cells use features of both innate-like and conventional $\mathrm{T}$ cells to recognize sulfatide self antigens. Nat Immunol 2012, 13:851-856

15. Patel O, Pellicci DG, Gras S, Sandoval-Romero ML, Uldrich AP, Mallevaey T, Clarke AJ, Le Nours J, Theodossis A, Cardell SL, Gapin L, Godfrey DI, Rossjohn J: Recognition of CD1d-sulfatide mediated by a type II natural killer $\mathrm{T}$ cell antigen receptor. Nat Immunol 2012, 13:857-863

16. Liu Y, Teige A, Mondoc E, Ibrahim S, Holmdahl R, IssazadehNavikas S: Endogenous collagen peptide activation of CD1d-restricted
NKT cells ameliorates tissue-specific inflammation in mice. J Clin Invest 2011, 121:249-264

17. Ishizu A, Ishikura H, Nakamaru Y, Takeuchi E, Kimura C, Koike T, Yoshiki T: Thy-1 induced on rat endothelium regulates vascular permeability at sites of inflammation. Int Immunol 1995, 7:1939-1947

18. Kyte J, Doolittle RF: A simple method for displaying the hydropathic character of a protein. J Mol Biol 1982, 157:105-132

19. Zajonc DM, Kronenberg M: CD1 mediated T cell recognition of glycolipids. Curr Opin Struct Biol 2007, 17:521-529

20. Ishizu A, Yoshiki T: Pathogenesis of vasculitis in env-pX Rats. Ann Vasc Dis 2012, 5:296-299

21. Zeng Z, Castano AR, Segelke BW, Stura EA, Peterson PA, Wilson IA: Crystal structure of mouse CD1: an MHC-like fold with a large hydrophobic binding groove. Science 1997, 277:339-345

22. Filipp FV, Sattler M: Conformational plasticity of the lipid transfer protein SCP2. Biochemistry 2007, 46:7980-7991

23. Girardi E, Wang J, Zajonc DM: Structure of an alpha-helical peptide and lipopeptide bound to the nonclassical major histocompatibility complex (MHC) class I molecule CD1d. J Biol Chem 2016, 291: 10677-10683

24. Schroeder F, Atshaves BP, McIntosh AL, Gallegos AM, Storey SM, Parr RD, Jefferson JR, Ball JM, Kier AB: Sterol carrier protein-2: new roles in regulating lipid rafts and signaling. Biochim Biophys Acta 2007, 1771:700-718

25. Hirai A, Kino $\mathrm{T}$, Tokinaga $\mathrm{K}$, Tahara $\mathrm{K}$, Tamura $\mathrm{Y}$, Yoshida S: Regulation of sterol carrier protein 2 (SCP2) gene expression in rat peritoneal macrophages during foam cell formation: a key role for free cholesterol content. J Clin Invest 1994, 94:2215-2223

26. Halder RC, Aguilera C, Maricic I, Kumar V: Type II NKT cellmediated anergy induction in type I NKT cells prevents inflammatory liver disease. J Clin Invest 2007, 117:2302-2312

27. Arrenberg P, Halder R, Kumar V: Cross-regulation between distinct natural killer $\mathrm{T}$ cell subsets influences immune response to self and foreign antigens. J Cell Physiol 2009, 218:246-250

28. Maricic I, Sheng H, Marrero I, Seki E, Kisseleva T, Chaturvedi S, Molle N, Mathews SA, Gao B, Kumar V: Inhibition of type I natural killer $\mathrm{T}$ cells by retinoids or following sulfatide-mediated activation of type II natural killer T cells attenuates alcoholic liver disease in mice. Hepatology 2015, 61:1357-1369

29. Terabe M, Swann J, Ambrosino E, Sinha P, Takaku S, Hayakawa Y, Godfrey DI, Ostrand-Rosenberg S, Smyth MJ, Berzofsky JA: A nonclassical non-V $\alpha 14 \mathrm{~J} \alpha 18$ CD1d-restricted (type II) NKT cell is sufficient for down-regulation of tumor immunosurveillance. J Exp Med 2005, 202:1627-1633

30. Liao CM, Zimmer MI, Shanmuganad S, Yu HT, Cardell SL, Wang CR: Dysregulation of CD1d-restricted type II natural killer T cells leads to spontaneous development of colitis in mice. Gastroenterology 2012, 142:326-334 